\title{
Aerodrome Flight Information Service
}

\author{
Jaromír Procházka \\ Department of Air Transport, \\ Department of Air Transport, Faculty of Transportation \\ Sciences, Czech Technical University \\ Horská 3, Praha 2, 128 03, Czech Republic \\ e-mail: xjprochazka@fd.cvut.cz
}

\begin{abstract}
The objective of this article is to describe aerodrome flight information service and activities provided by AFIS officer and also highlight potential improvements.
\end{abstract}

\section{Key words: AFIS; aerodrome; flight information service}

\section{INTRODUCTION}

General aviation is vital part of professional flying and there are many reasons for it. Each professional pilot has to be trained first on the field of general aviation and thereafter continues in professional manner. Behaviors which are gotten at the beginning of the training are radical part of pilots training. There is necessary to say that importance of the start is fundamental.

Parts of general aviation are also hobby flying (just for fun), air works, aviation school activity, parachute jumping, gliding and so on. There are different kinds of traffic which could be met at the aerodrome and therefore we have to set exact regulation to avoid any mistakes. An impact from the mistakes could be fatal.

All aviation activities have their own regulations which help to define above mentioned activity activities and responsibility of each traffic participant. Some of the regulations were historically generated from accidents and incidents. This regulation was subsequently implemented into aviation environment. Pilots took these new things with some resistance at the beginning. Nevertheless the things are taken as integral part of general aviation and no one is considering that it was unnecessary nowadays.

\section{AFIS}

One of the inseparable parts of aviation is Aerodrome Flight Information Service which is commonly known as AFIS. AFIS is established at uncontrolled aerodromes. The main purpose of AFIS is providing information about traffic in the vicinity of the aerodrome. The workplace was established on the foundation of experience. It was shown that providing information to the pilots is very useful and it can preclude serious troubles (enhance situation awareness which improve safety in aerodrome traffic zone). Main tasks of AFIS can be divided into four basic sections:
a) to inform about surrounding traffic
b) distribution of meteorological information
c) coordination of using runways

\author{
Vladimír Plos \\ Department of Air Transport, \\ Department of Air Transport, Faculty of Transportation \\ Sciences, Czech Technical University \\ Horská 3, Praha 2, 128 03, Czech Republic \\ e-mail: plosvlad@fd.cvut.cz
}

d) initiating and assistance for search and rescue team in case of accident

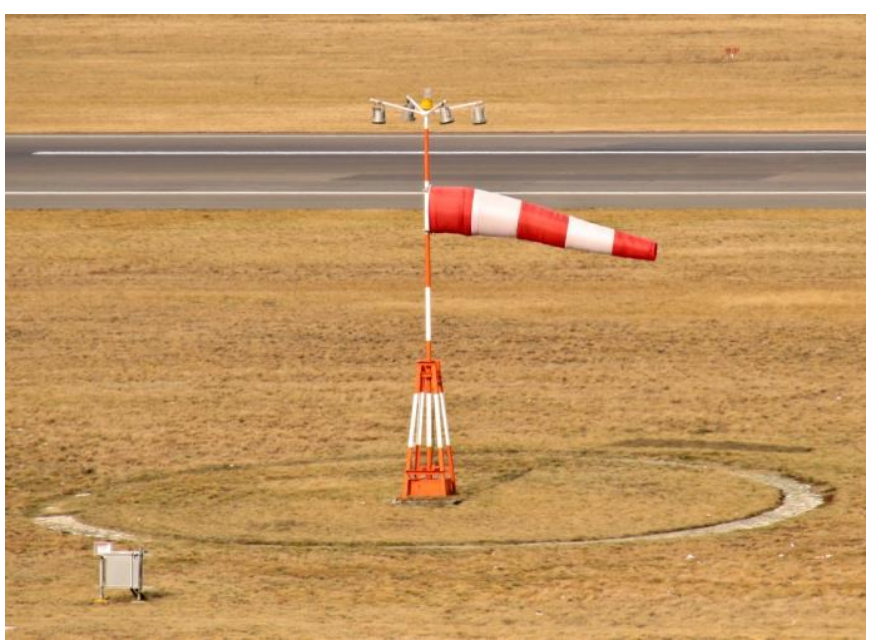

Figure 1 - Source of meteorological information

\section{AFIS ACTIVITIES}

Activities mentioned above were given to AFIS as a main responsibility and of course everything was written into the aviation law. There was established one person for aerodrome in the Czech Republic because density of traffic was not demand multi crew at the AFIS. AFIS officer is a trained person, holder of AFIS license. Another license which must be held is general radio telephony license, published by Czech telecommunication institute. It is necessary to pass the exams to get the license. The exam is divided into three parts. First part deals with radio communication law, where are examine the applicants knowledge from the law. Main goal is to check the familiarity with Annex 10 part 2. Second part of exam deals with electronic. Hereby the applicant is questioned about knowledge concerning physical laws, electronic devices which will be used in real environment and some other things connected with electro-magnetic world. Last part of the exam is radio communication in real situations. There is necessary to prove the knowledge namely about phase of flight, correct phraseology, using phraseology in correct time and sequence. After passing above mentioned parts, which are written, applicant is familiarized with his results and if the results are on appropriate level he can take oral part of exam. There is necessary to show the 
ability to speak fluently in English language and then follows checking of phraseology again. The whole examination process takes about half a day and if all parts are done, the applicant is given a radiotelephony license. This license is divided basically in two types - the restricted and general. For our purpose let's say radio telephony license.

After all procedures the applicant is qualified for working at the aerodrome as AFIS officer when receiving these two licenses. But experience showed that all applicants must get proper training on assigned workplace before starting to control the traffic. All small aerodromes are different and there is necessary to point out different details and show how to work with specific type of radios at the workplace. Differences are mainly in types of radios, also exists various kinds of equipment for measuring winds and last but not least some uncontrolled aerodromes have their own frequency for transmission of information like runway in use, meteorological conditions and so on. It is unfortunately normal situation that no check list exists for purpose of checking the necessary things that might be done before commencing of duty. There are no rules how to take over control among AFIS officers. Above mentioned facts are only few things which must be done and there is one more important thing - the real operations. Everyone has to start and we cannot blame anyone because everything is so complicated at the beginning so as with the beginners at AFIS station. There is only small amount of uncontrolled aerodromes in Czech Republic which has built up program for indoctrinate a new applicant into the AFIS process. Sometimes might be helpful to let him work under supervision of some experience colleague.

\section{A. To inform about surrounding traffic}

This is main task of the AFIS officer and nearly all duty is fulfilled by this work. Rarely is officer exposure of necessity to worn the traffic against other traffic to revert imminent threats. Let's say that it is continuous watching of traffic flow in the aerodrome traffic zone.

For an example aerodrome Benešov was very popular last years and therefore a lot of operations were made at the aerodrome. Aerodrome has ICAO identification LKBE and is covered by grass with two runways with magnetic bearings $09 / 27$ and $06 / 24$. The runways are approximately 750 meters long. The altitude of the aerodrome Benešov is nearly the same as international aerodrome Ruzyně. The terrain surroundings the LKBE is quite convenient if we take the south, west and east part. On the north there is a rugged terrain, not so suitable if we are thinking about possibility of unexpected maneuver or emergency landing.

Operating hours are state in the summer season from early morning until sunset. This fact is quite common because the weather is most favorable in this part of the year. There is mainly engine airplanes traffic, ultralight traffic and some gliders. Sometimes parachute jumping can occur and it is not an exception on such busy days that almost twenty actions are taken in one moment in aerodrome traffic zone and it is almost impossible to coordinate them without proper skills and a lot of experiences. Everyone involved in such situation must clearly recognize their necessity to make an announcement to prevent any dangerous situation and AFIS officer's calls must be followed by quick response. It is evident that role of dispatcher is vital and all aerodrome traffic is quite influenced by his skills.

For better understanding we can draw a situation which can explain the action in aerodrome traffic zone. Let's say that on the aerodrome traffic circuit patterns are two students practicing their first touch and go landings. It is natural that special attention must be made for theses pupils because nobody can expect unexpected. There is a lot of other traffic in the same time with different demands like to fly into the airspace or just pass through the air traffic zone. Someone is making photos above his house and his airplane is still in the traffic zone. Gliders can be as fast as possible in the air because updrafts are not waiting and on the contrary the towing airplane must be as fast as possible on the ground because every minute cost a lot of money.

It is highly important to keep proper phraseology in such environment and keep strictly the orders of aviation laws. We can see that AFIS officer hasn't easy job and he must strictly separate essential and nonessential messages.

\section{B. Distribution of meteorological information}

Meteorological activity of AFIS officer is not easy. It is expected from him to watch the present weather and also to interpret the TAF, SIGMETS for pertinent territory. Main activity is than derive some predictive conditions which will influence the airport. Relevant information for airman is wind direction, wind strength, temperature, dew point etc.

Predictive activities are expecting a little bit more than good knowledge of meteorology. It is advantage of experienced officers that they are able to make their own prediction based on experiences. To predict and forecast local weather behavior has great influence on aerodrome traffic. Let's see another example. We are just now standing at the airport of Leoš Janáček in Ostrava. We are planning to fly via Benešov and we would like to make full stop landing there to get the fuel and have a rest. We can watch and review perfectly the actual METAR and TAF for the area and we decided to make the flight. But after two hours of flying we are close to LKBE and we can see mostly nothing because local terrain and local weather behavior was different than general prediction based on general rules and overall situation. Our trip is terminated in better case by landing on different aerodrome which was not scheduled and we don't know mostly anything about it. If we make a call to AFIS LKBE before our flight when we were in Ostrava on the ground and meet an experienced officer at Benešov and after asking him about meteorological situation he will give us a very good overview of the situation. He would give us a prediction that in time of our intended landing there will be bad weather at LKBE aerodrome and his good advice will be to postpone the arrival until 
bad weather will be gone. Or we can make an alternative plan to avoid unexpected circumstances.

\section{Coordination of using runways}

It is a duty of AFIS officer to coordinate RWY direction for landings and take offs. No other person can have a general overview about actual situation at the aerodrome, local situation and special influences which may affect runway in use. The AFISO (AFIS Officer) in charge must keep watching the meteorological situation during all duty and in case of change of wind direction must take an action. The direction of wind and strength as well is important from many reasons. First of all it is not easy to properly land the airplane when the wind is near or at the same level of direction of strength limits which airplane can take. If we search through the aircraft flight manual we can meet a directive about maximum limits of wind strength for take offs and landings.

The way how to transmit the information about runway in use is simple and very effective. There is a cautionary square at the aerodrome and there are some significant marks which indicate runway direction in use and any other useful information. Some, but not a lot, uncontrolled aerodrome have their own special frequency for transmitting such information so it could be taken mostly like an exception. There could be even information above contamination of the runways or such info like cutting grass at the aerodrome. Above mentioned situation are mostly provided by AFISO after initial contact with AFIS station.

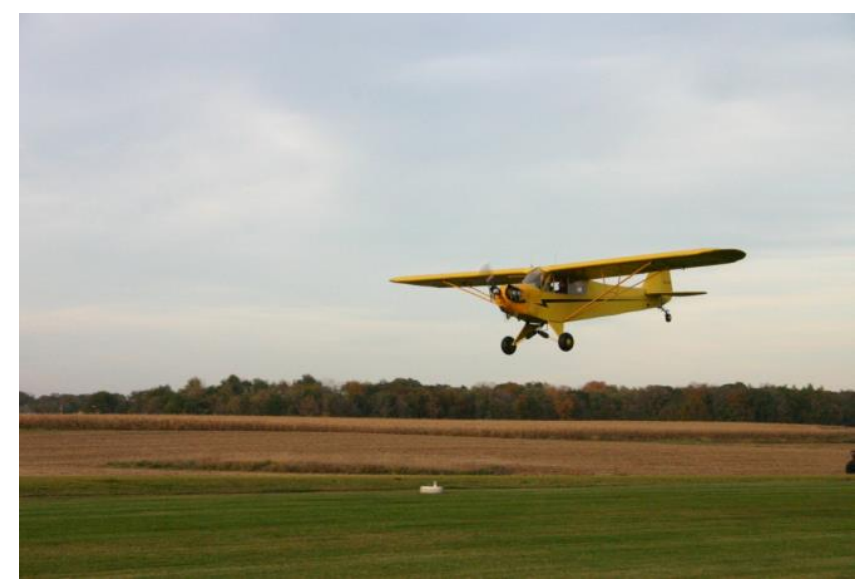

Figure 2 - ATZ traffic

\section{Initiating and assistance for search and rescue team in case of accident}

AFIS officer's duty is to call emergency vehicles and all other organs which must be involved in the emergency situation. All such actions which must be taken are stated in aerodrome directive list which is nowadays integral part of AFIS station nowadays. Let's take an example: we are witness of emergency situation like crash of an airplane. The first step is to stop and inform all traffic in the aerodrome traffic zone to prevent cumulative accidents. AFIS officer can give an order in such situations. After all operations were stopped on pertinent runway, it is necessary to call appropriate organs - ambulance, police and fire brigade. The situation must be monitored and all steps have to be written down for consequent testimony.

\section{IV. ... AND THEIR IMPROVEMENT}

All above mentioned duties are core of AFIS officer job. If we take the problematic more general we can think of more things which may be done by AFIS station. However it's important to say that it is an activity where there is a huge space for improvements. The job of AFIS officer is voluntary on the majority of aerodromes so we cannot expect any improvement soon because there is no natural pressure of competition which brings better service for aviators.

One of the possible improvements could be to create check lists for AFIS station. This method is widely used and well known in aviation and there could not be a problem to implement it into real operations. The officer will come to work and make all steps according to check lists - all radio station will work correctly, volume will be up, receivers will be tuned etc. - step by step. Each action will have its own check list and there will be prescribed sequence of the check lists for different events.

Another improving step could be better education of participant in air operations. All fast grown pilots have problems with radio communication because to be a pilot, there is only necessary to pass an exams and finish. If there is an organization which will be responsible for educating proper use of radios, phraseology and training it could help.

Finally we can state that almost everything is just question of sources but there are many things which could be improved only by changing the system and adopting new approaches. Naturally commercial air transport is under higher pressure and all effort is focused in that direction. But each pilot has to grow up from general aviation and behavior which he takes from that time will be with him his entire professional carrier.

\section{CONCLUSION}

In this article we described Aerodrome Flight Information Service, which is the core of aerodromes for general aviation. It can be seen, that this core could work harder. It just need slight impulse from any authority in civil aviation.

The four main activities could be extended of some more. There is room for it, but only when AFIS became more sophisticated than today. Some examples for improvement are described in chapter 3 .

\section{ACKNOWLEDGEMENTS}

This paper was supported by the Grant Agency of the Czech Technical University in Prague, grant No. SGS12/165/OHK2/2T/16. 


\section{REFERENCES}

[1] Letecký předpis L 11 - Letové provozní služby. [online]. Available at <http://lis.rlp.cz/predpisy/predpisy/index.htm>

[2] Eurocontrol AFIS manual. [online]. Eurocontrol. Available at <http://www.skybrary.aero/bookshelf/books/1446.pdf>

[3] AIP ČR [online]. Available at

〈http://lis.rlp.cz/ais_data/www_main_control/frm_cz_aip.htm>

[4] CAA/S-SLS-004-0/2011. Směrnice pro osvědčování poskytovatelů letištních letových informačních služeb (AFIS). Úrad pro civilní letectví [online]. Available at $<$ http://www.caa.cz/download/pdf/CAA_S-SLS-0040_2011.pdf> 